\title{
BAP1 germline mutation in two first grade family members with uveal melanoma
}

\author{
David A Maerker, ${ }^{1}$ Michael Zeschnigk, ${ }^{2}$ Jasmin Nelles, ${ }^{2}$ Dietmar R Lohmann, ${ }^{2}$ \\ Karl Worm, ${ }^{3}$ Anja K Bosserhoff, ${ }^{4}$ Rosemarie Krupar, ${ }^{4}$ Herbert Jägle ${ }^{1}$
}

${ }^{1}$ Department of

Ophthalmology, University of Regensburg, Germany

2Eye Cancer Research Group, Faculty of Medicine, Institute for Human Genetics, University of Duisburg Essen, Essen, Germany

${ }^{3}$ Faculty of Medicine, Institute for Pathology and Neuropathology, University of Duisburg Essen, Essen, Germany

${ }^{4}$ Institute of Pathology, University of Regensburg, Regensburg, Germany

\section{Correspondence to} Dr David Arthur Maerker, Department of Ophthalmology, University of Regensburg, Franz-Josef-Strauss-Allee 11, Regensburg 93042, Germany; maerker@eye-regensburg.de

Received 4 June 2013 Revised 1 October 2013 Accepted 10 October 2013 Published Online First 1 November 2013
To cite: Maerker DA, Zeschnigk M, Nelles J, et al. Br J Ophthalmol 2014;98:224-227.

\section{ABSTRACT \\ Background Uveal melanoma (UM) is the most} common primary cancer of the eye in adults. About half of the patients are at risk of developing metastatic disease resulting in a poor clinical prognosis. Metastatic progression is strongly associated with loss of one chromosome 3 in the tumour (monosomy 3). The tumour suppressor gene $B A P 1$ was found to be recurrently mutated in UM with monosomy 3 . Familial UM is rare and amounts to about $0.6-6 \%$ of all patients with melanoma. However, BAP1 germline mutations have been identified in rare hereditary tumour syndromes, including cases with UM. One may assume that UM may be part of these hereditary conditions with predisposition to malignant cancers.

Methods The patients underwent complete ophthalmological workup and enucleation due to UM. Microsatellite analysis was performed to determine the chromosome 3 status of the tumours. Sanger sequencing of all coding exons of the BAP1 gene was performed in blood DNA of the patients.

Results Here we report on two family members (mother and son) diagnosed with UM. In both patients, a cosegregating BAP1 germline mutation (c.299 T>C) was found. The mutant $B A P 1$ allele was retained in the tumour of the son showing monosomy 3 . The son further developed urothelial carcinoma and liver metastasis, the mother was affected by the UM and cholangiocellular carcinoma.

Conculsions We detected a cosegregating BAP1 germline mutation in two family members with UM. This suggests that, consistent with a classic tumour suppressor model, carriers of damaging mutations in $B A P 1$ are predisposed to UM. However, as BAP1 germline mutations have been found to cause other cancer syndromes as well, there must be other factors that decide about the type of tumour emerging from $B A P 1$ inactivation.

\section{INTRODUCTION}

Uveal melanoma (UM) is the second most common form of melanoma and the most common primary cancer of the eye in adults and has a strong propensity for fatal metastasis. ${ }^{1}$ The exact aetiology of this cancer remains unclear. UM can arise anywhere in the uveal tract including ciliary body and choroid. Frequently, more than one of these structures are involved. UM is usually sporadic and the average age at diagnosis of primary tumour is in the mid-50s. However, there are rare cases of familial UM, comprising only $\sim 0.6-6 \%$ of all patients with UM. $^{2}{ }^{3}$ There are 73 such cases documented in the literature, including the family in this report. ${ }^{4-6}$
Loss of one chromosome 3 (monosomy 3 ) in the tumour is strongly associated with metastatic death of patients suggesting that inactivating mutations of a gene on the remaining chromosome 3 promotes metastasis. $^{7}$

$B A P 1$, which maps to $3 \mathrm{p} 21$, codes for an ubiquitin carboxy-terminal hydrolase that interacts with the Really Interesting New Gene (RING) finger domain of the breast cancer 1 early onset protein (BRCA1). ${ }^{8}{ }^{9}$ This gene is thought to be a tumour suppressor gene that functions in the BRCA1 growth control pathway. ${ }^{8} 10$ In BRCA1 mutation carriers, multiple neoplasms and family history of breast cancer occur frequently. A higher frequency of $\mathrm{UM}$ in BRCA germline mutation carriers than predicted has been reported recently. ${ }^{11}$

Lately, Harbour et al ${ }^{12}$ reported BAP1 inactivating mutations which were predominantly found in UMs with high metastatic potential. BAP1 germline truncating mutation predispose to a hereditary cancer syndrome including UM, lung adenocarcinoma, neuroendocrine carcinoma, meningioma, cutaneous melanoma and possibly other cancers. ${ }^{13}$ Additionally, Wiesner et al ${ }^{14}$ described an autosomal dominant syndrome that is caused by germline mutations of $B A P 1$, characterised by a high penetrance of melanocytic neoplasms possibly associated with an increased risk for uveal and cutaneous melanomas. Here we report a germline BAP1 mutation cosegregating with UM in two affected first degree family members.

\section{METHODS}

\section{Patients}

Informed consent of the patients was obtained; the study was in adherence to the tenets of the Declaration of Helsinki. Mother and son underwent complete ophthalmological workup including slit lamp examination, funduscopy, gonioscopy, a-scan and b-scan ultrasound, and as far as needed fluorescein angiography. The primary tumours of both patients were treated by enucleation. Histopathological analysis was performed.

\section{Genetic analyses}

The son's tumour DNA was isolated from fresh frozen tumour as described elsewhere. ${ }^{15}$ DNA from the mother's tumour was prepared from formalin fixed paraffin embedded tumour tissue using the QIAamp DNA Mini Kit (Qiagen, Hilden, Germany) following the protocol: 'Isolation of genomic DNA from paraffin-embedded tissue'.

Chromosome 3 typing was performed by microsatellite analysis using eight chromosome 3 markers as described elsewhere. ${ }^{15}$ Sequence analysis of all 


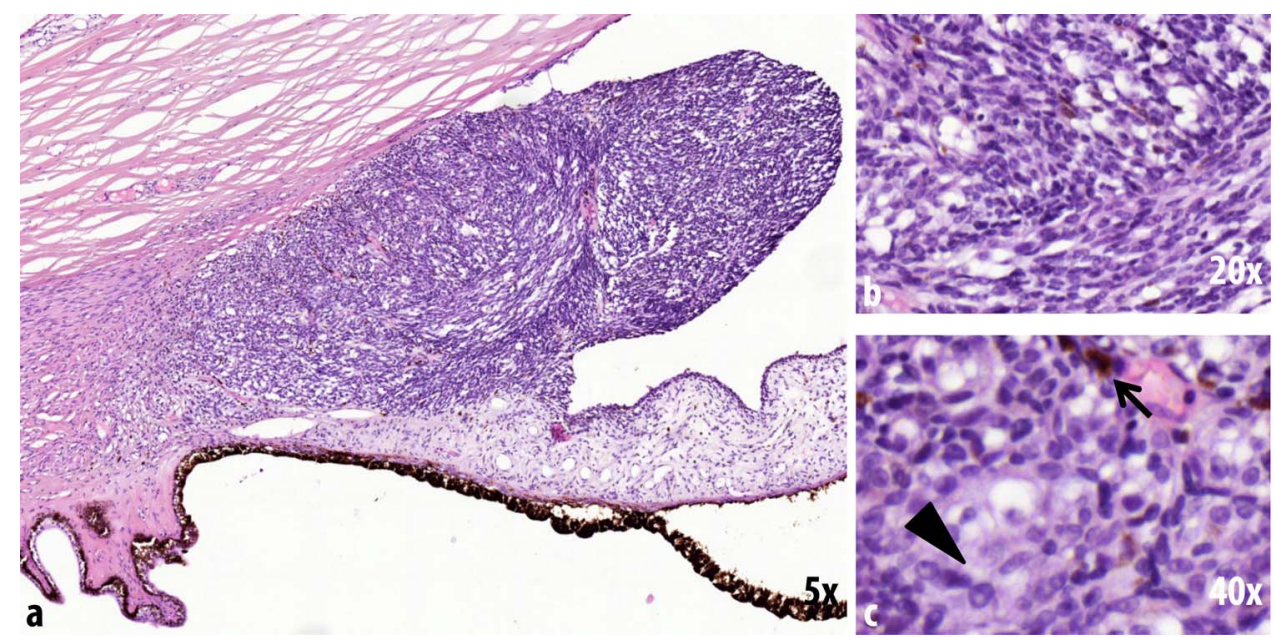

Figure 1 H\&E staining of the ciliary body melanoma of the mother. (A) Mixed-cell malignant melanoma of the ciliary body and iris with infiltration of the trabecular meshwork (magnification $5 \times$ ). (B) The tumour is composed of tightly-packed bundles of spindle-shaped cells (magnification 20x). (C) Slender nuclei and epitheloid cells (arrowhead) with abundant eosinophilic cytoplasm, large nuclei and prominent nucleoli as well as a few pigmented cells (arrow) are visible (magnification 40x). Access the article online to view this figure in colour.

BAP1 exons was performed on genomic DNA from blood cells and tumour tissue. Oligonucleotide primers were designed to amplify all 17 BAP1 exons. ${ }^{16}$ PCR was performed on $20 \mathrm{ng}$ genomic DNA using Green GoTaq DNA Polymerase (Promega, Madison, USA) in a total volume of $25 \mu \mathrm{L}$ following the manufacturer's instructions. Annealing temperature for all primers was set to $62^{\circ} \mathrm{C}$. Sanger sequencing was performed with routine methods using the PCR primers. BAP1 mutation (c.299T $>$ C) refers to cDNA with accession number NM_004656.2.
Figure 2 Clinical evaluation of the son before treatment. (A) Slit lamp examination: visible tumour in the chamber angle at 5.30 o'clock position. (B) Gonioscopy: tumour mass in the chamber angle. (C) Slit lamp examination with dilated pupil: tumour mass visible behind the lens. (D) Slit lamp examination in retroillumination: intravitreal tumour mass. (E) B-scan ultrasound: mushroom shaped melanoma of the choroid. (F) A-scan ultrasound: low reflectivity of tumour tissue. Access the article online to view this figure in colour.
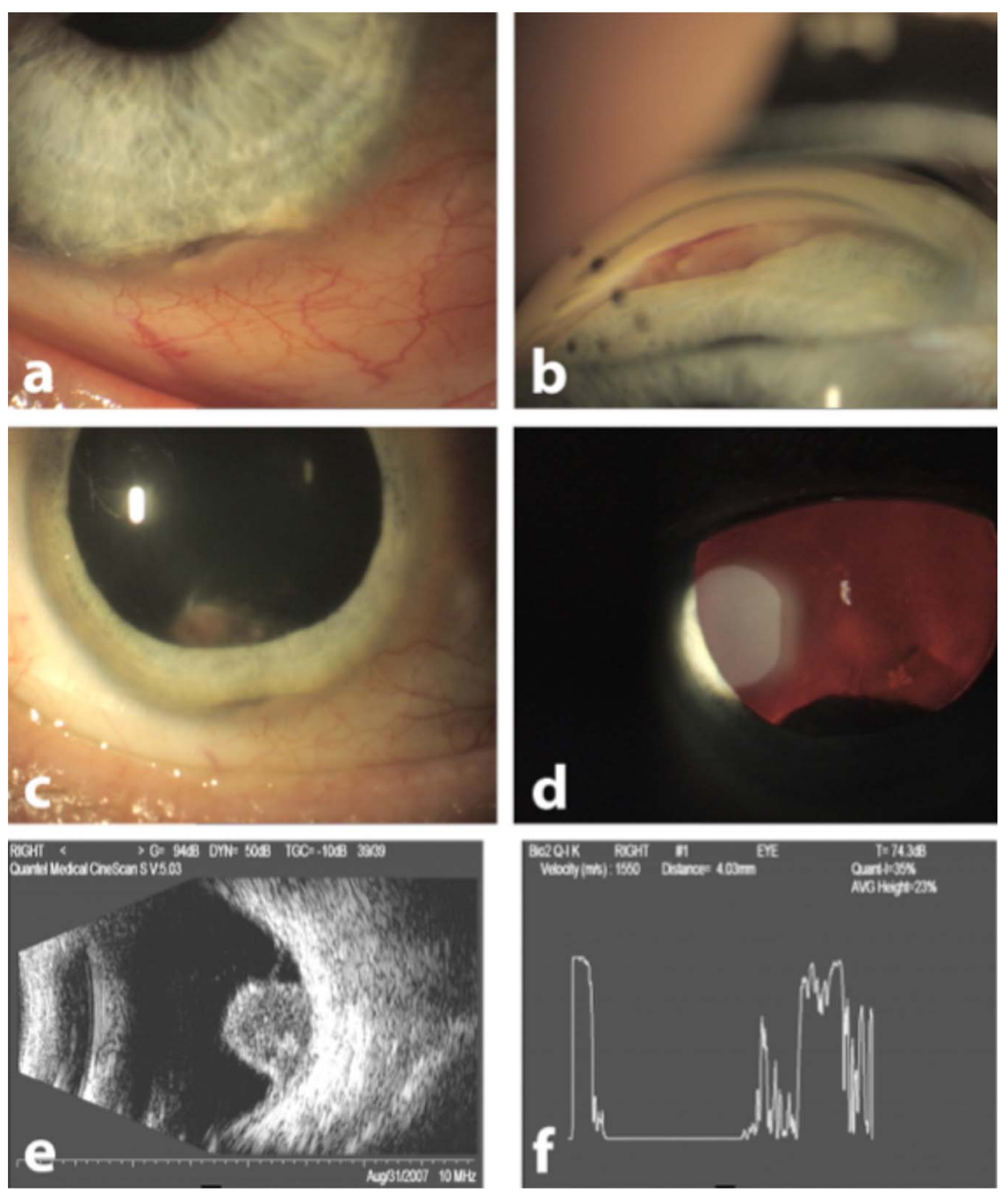


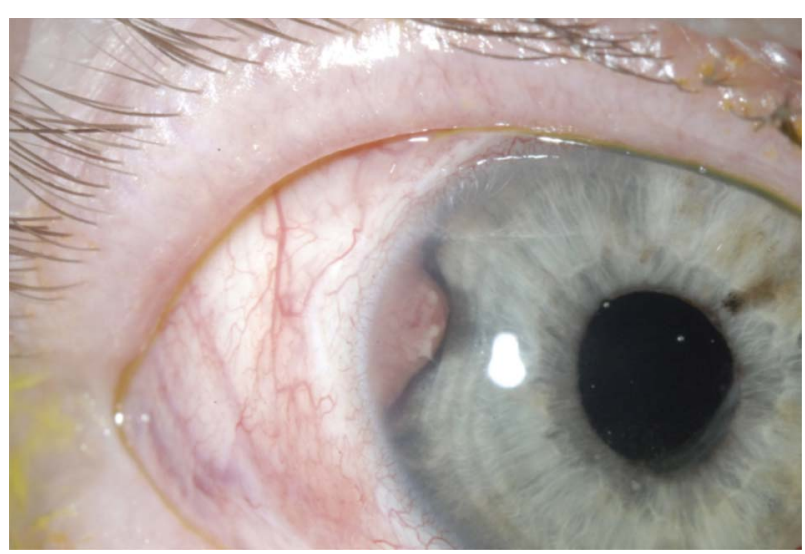

Figure 3 Slit lamp examination of the anterior segment: visible recurrence of the tumour in the chamber angle at the 9 o'clock position. Access the article online to view this figure in colour.

\section{RESULTS}

In 1997, the mother was diagnosed with UM of the ciliary body at the age of 56 years. Since 1991 a tumour of the chamber angle from the 6 o'clock to 10 o'clock position was controlled. After development of secondary glaucoma with intraocular pressure as high as $40 \mathrm{~mm} \mathrm{Hg}$, a biopsy of the tumour was performed and an UM with involvement of the ciliary body was diagnosed. Therefore the eye was enucleated. Histological analysis revealed an UM of mixed cellular structure which affected the ciliary body and iris (figure 1). An infiltration of the trabecular meshwork could be observed. There was no evidence for metastasis in 1998. Since then, the patient has not developed metastasis. In February 2012 an intrahepatic cholangiocellular carcinoma was diagnosed and treated by resection. In October, a relapse was treated by hemihepatectomy. Since then, no other neoplasms have developed and the patient is of good health now.

The son was diagnosed with UM in 2007 at the age of 45 years. Initially, a tumour of the chamber angle was observed by slit lamp examination and gonioscopy (figure 2A,B). With dilated pupil and in retroillumination, a prominent intravitreal tumour mass was present (figure 2C,D). B-scan ultrasonography showed a mushroom shaped UM (figure 2E). A-scan ultrasonography revealed low reflectivity (figure $2 \mathrm{~F}$ ). The maximal prominence of the tumour was $6 \mathrm{~mm}$ to the sclera. The patient underwent proton radiation in November 2007, followed by a trans-scleral tumour resection in December 2007. In February 2008, May 2009 and July 2009, a recurring retinal detachment was finally successfully treated by silicone oil tamponade.

In February 2010, an urothelial carcinoma was treated by operation and sixfold local chemotherapy. In February 2011 a recurrence of the ciliary body tumour was noted (figure 3) and the eye was enucleated in March 2011. Histological analysis revealed a nodular proliferating melanoma composed of pleomorphic eosinophilic cells with pleomorphic, eccentrically localised nuclei (figure 4). The patient was diagnosed with liver metastasis in segments 5, 7 and 8 in July 2011 and was treated by local radio frequency thermal ablation without obtaining a biopsy.

Mother and son did not smoke or were exposed to chemicals. Dermatological workup of the patients and family members did not reveal cutaneous melanoma or atypical cutaneous naevi.

Genotyping of the tumour DNAs of the mother and son by microsatellite analysis using eight chromosome 3 markers ${ }^{15}$ revealed loss of heterozygosity of all informative markers, consistent with monosomy 3. Sequence analysis of all 17 exons of the BAP1 gene in DNA from the son's tumour revealed a missense mutation (c.299T $>$ C) in exon 5. The same mutation was detected at heterozygous state in the blood DNAs from the son and the mother (figure 5) by Sanger sequencing. Other family members did not undergo BAP1 sequencing.

There was no history of UM, breast or ovarian cancer in any other family member, but the pedigree revealed several other neoplasias (figure 6).

\section{DISCUSSION}

Several lines of evidence strongly suggest that BAP1 plays a major role in tumour development. Harbour et $a l^{12}$ found inactivating somatic mutations in 26 of 31 (84\%) metastasising tumours and usually BAP1 mutations are seen on the remaining allele in tumours with monosomy 3 . As the two-step mutational inactivation of this gene complies with the classical tumour suppressor gene model, it is plausible that inactivating $B A P 1$ germline mutations can be a cause of inherited predisposition to this cancer. Familial UM is reported to be a rare condition comprising only $\sim 0.6-6 \%$ of all patients with UM. ${ }^{2} 3$

In the present study, we report on a BAP1 germline mutation associated with familial UM. In the tumour of the son, monosomy 3 was observed with the mutated BAP1 allele retained
Figure $4 \mathrm{H} \& \mathrm{E}$ staining of the melanoma of the ciliary body of the son. (A) Uveal melanoma with nodular growth pattern and infiltration of the ciliary body ( $5 \times$ magnification). (B) The uveal melanoma is composed of highly atypical melanocytes with abundant eosinophilic cytoplasm, eccentrically located, pleomorphic and hyperchromatic nuclei and prominent nucleoli (arrow). Some tumour cells are pigmented. A few multinucleated tumour cells (arrowhead) and atypical mitoses (20x magnification). Access the article online to view this figure in colour.
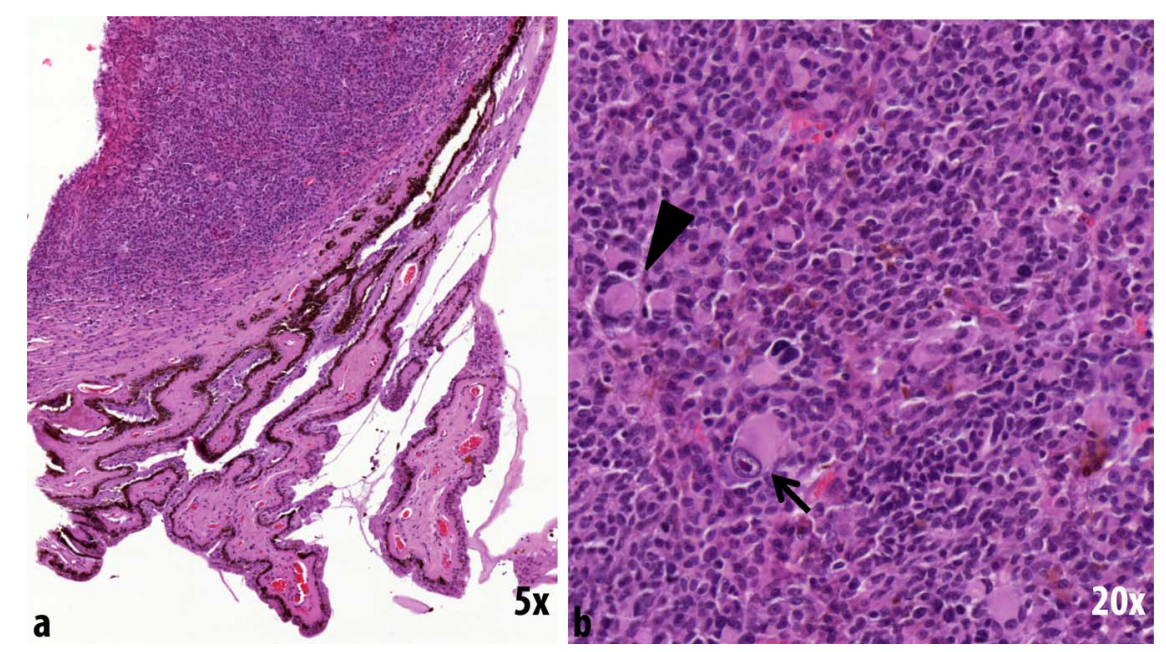
Figure 5 Sanger sequencing of $B A P 1$ exon 5 demonstrating a heterozygous mutation (c.299 T>C, indicated by arrows) in blood DNA from the affected patients (mother and son). The tumour of the son shows loss of the normal allele. The electropherogram shows a heterozygous $\mathrm{T}>\mathrm{C}$ substitution that replaces Leucine by Proline at codon 100. Access the article online to view this figure in colour. blood
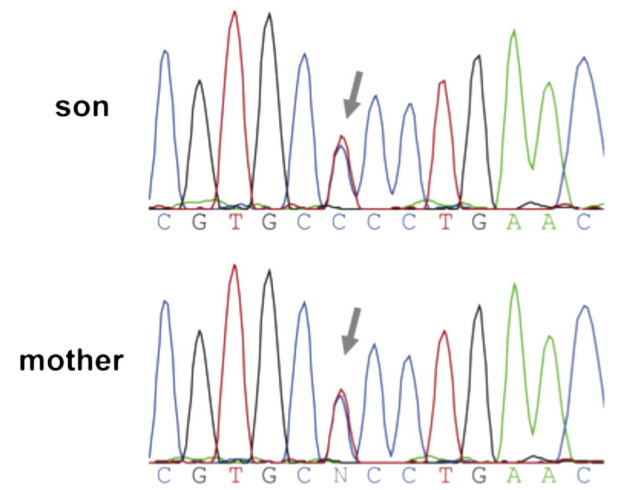

tumour

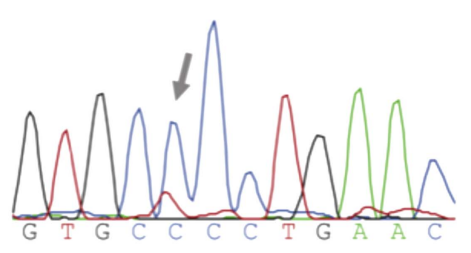

suggesting complete inactivation of BAP1. This is in concordance with an assumed tumour suppressor gene function of $B A P 1$. The missense mutation found in exon 5 of the BAP1 gene causes replacement of Leucine with Proline at codon 100 (L100P). We used Sorting Intolerant From Tolerant (SIFT) and Polyhen-2 to predict whether the amino acid substitution affects $B A P 1$ protein function. ${ }^{17}{ }^{18}$ According to both algorithms, the change in amino acid sequence of BAP1 as found in the affected patients is classified as damaging, with a PolyPhen-2 probability score of 1 .

Although both patients carry the same germline mutation, the course of disease is different. Age at diagnosis of the primary UM was 56 years for the mother and thereafter no other neoplasia was diagnosed. With 45 years of age, the son was much younger when diagnosed with UM. Shortly after, he has been diagnosed with a second tumour and metastatic UM suggesting a more severe course of disease. Previously BAP1 germline mutations have been reported to cosegregate with other tumours such as mesothelioma or melanocytic tumours in other families. ${ }^{12} 13$

The results of our study provide further evidence that BAP1 germline mutations predispose to tumours including UM. However, the predominant type of tumour varies between different families thus the tumour entity might depend on
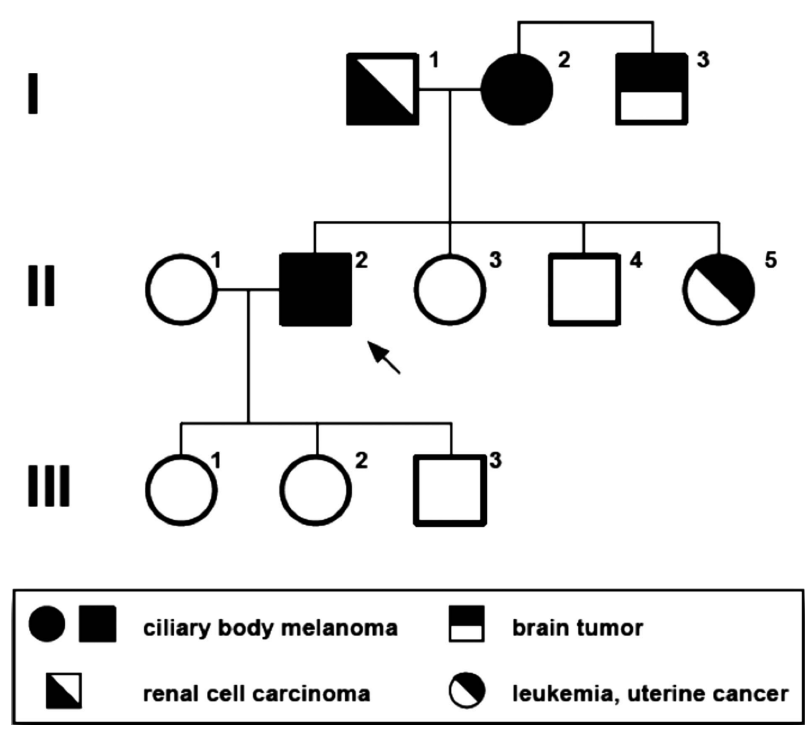

Figure 6 Pedigree of the family with inherited uveal melanoma. Only the patients affected by uveal melanoma $(I .2, I .2)$ were examined at the Department of Ophthalmology, University of Regensburg. additional factors. More families with BAP1 germline mutation have to be identified and investigated to determine these factors.

Contributors The study was conducted by $\mathrm{HJ}$ and DAM. MZ, JN and DRL contributed by genetical analyses. AKB and RK contributed by pathological workup. Competing interests None.

Ethics approval

Provenance and peer review Not commissioned; externally peer reviewed.

\section{REFERENCES}

1 Landreville S, Agapova OA, Harbour JW. Emerging insights into the molecular pathogenesis of uveal melanoma. Future Oncol 2008;4:629-36.

2 Harbour JW. The genetics of uveal melanoma: an emerging framework for targeted therapy. Pigment Cell Melanoma Res 2012;25:171-81.

3 Singh $A D$, Shields $C L$, De Potter $P$, et al. Familial uveal melanoma. Clinical observations on 56 patients. Arch Ophthalmol 1996;114:392-9.

4 Barker-Griffith AE, Streeten BW. Familial uveal melanoma: a report of four cases in two families and literature review. Canadian journal of ophthalmology. Can J Ophthalmol 2004;39:403-8.

5 Kodjikian L, Nguyen K, Lumbroso L, et al. Familial uveal melanoma: a report on two families and a review of the literature. Acta Ophthalmol Scand 2003;81:389-95.

6 Smith JH, Padnick-Silver L, Newlin A, et al. Genetic study of familial uveal melanoma: association of uveal and cutaneous melanoma with cutaneous and ocular nevi. Ophthalmology 2007;114:774-9.

7 Prescher $\mathrm{G}$, Bornfeld $\mathrm{N}$, Hirche $\mathrm{H}$, et al. Prognostic implications of monosomy 3 in uveal melanoma. Lancet 1996;347:1222-5.

8 Jensen DE, Proctor M, Marquis ST, et al. BAP1: a novel ubiquitin hydrolase which binds to the BRCA1 RING finger and enhances BRCA1-mediated cell growth suppression. Oncogene 1998;16:1097-112.

9 Misaghi S, Ottosen S, Izrael-Tomasevic A, et al. Association of C-terminal ubiquitin hydrolase BRCA1-associated protein 1 with cell cycle regulator host cell factor 1. Mol Cell Biol 2009;29:2181-92.

10 Nishikawa $\mathrm{H}, \mathrm{Wu}$ W, Koike A, et al. BRCA1-associated protein 1 interferes with BRCA1/BARD1 RING heterodimer activity. Cancer Res 2009;69:111-19.

11 Cruz C, Teule A, Caminal JM, et al. Uveal melanoma and BRCA1/BRCA2 genes: a relationship that needs further investigation. J Clin Oncol 2011;29:e827-9.

12 Harbour JW, Onken MD, Roberson ED, et al. Frequent mutation of BAP1 in metastasizing uveal melanomas. Science 2010;330:1410-13.

13 Abdel-Rahman MH, Pilarski R, Cebulla CM, et al. Germline BAP1 mutation predisposes to uveal melanoma, lung adenocarcinoma, meningioma, and other cancers. J Med Genet 2011;48:856-9.

14 Wiesner T, Obenauf AC, Murali R, et al. Germline mutations in BAP1 predispose to melanocytic tumors. Nat Genet 2011;43:1018-21.

15 Tschentscher $F$, Prescher G, Zeschnigk M, et al. Identification of chromosomes 3, 6, and 8 aberrations in uveal melanoma by microsatellite analysis in comparison with comparative genomic hybridization. Cancer Genet Cytogenet 2000;122:13-17.

16 Martin $M$, Masshofer $L$, Temming $P$, et al. Exome sequencing identifies recurrent somatic mutations in EIF1AX and SF3B1 in uveal melanoma with disomy 3. Nat Genet 2013;45:933-6.

17 Adzhubei IA, Schmidt S, Peshkin L, et al. A method and server for predicting damaging missense mutations. Nat Methods 2010;7:248-9.

18 Kumar P, Henikoff S, Ng PC. Predicting the effects of coding non-synonymous variants on protein function using the SIFT algorithm. Nat Protoc 2009;4:1073-81. 


\section{BAP1 germline mutation in two first grade family members with uveal melanoma}

David A Maerker, Michael Zeschnigk, Jasmin Nelles, Dietmar R Lohmann, Karl Worm, Anja K Bosserhoff, Rosemarie Krupar and Herbert Jägle

Br J Ophthalmol 2014 98: 224-227 originally published online November 1,2013

doi: 10.1136/bjophthalmol-2013-303814

Updated information and services can be found at:

http://bjo.bmj.com/content/98/2/224

\section{These include:}

References This article cites 18 articles, 5 of which you can access for free at: http://bjo.bmj.com/content/98/2/224\#BIBL

Email alerting Receive free email alerts when new articles cite this article. Sign up in the service box at the top right corner of the online article.

Topic Articles on similar topics can be found in the following collections Collections

$$
\text { Eye (globe) (708) }
$$

\section{Notes}

To request permissions go to:

http://group.bmj.com/group/rights-licensing/permissions

To order reprints go to:

http://journals.bmj.com/cgi/reprintform

To subscribe to BMJ go to:

http://group.bmj.com/subscribe/ 